\title{
Cluster-like headache secondary to trigeminal meningioma
}

Figure MRI demonstrating a tumor arising from the left trigeminal nerve
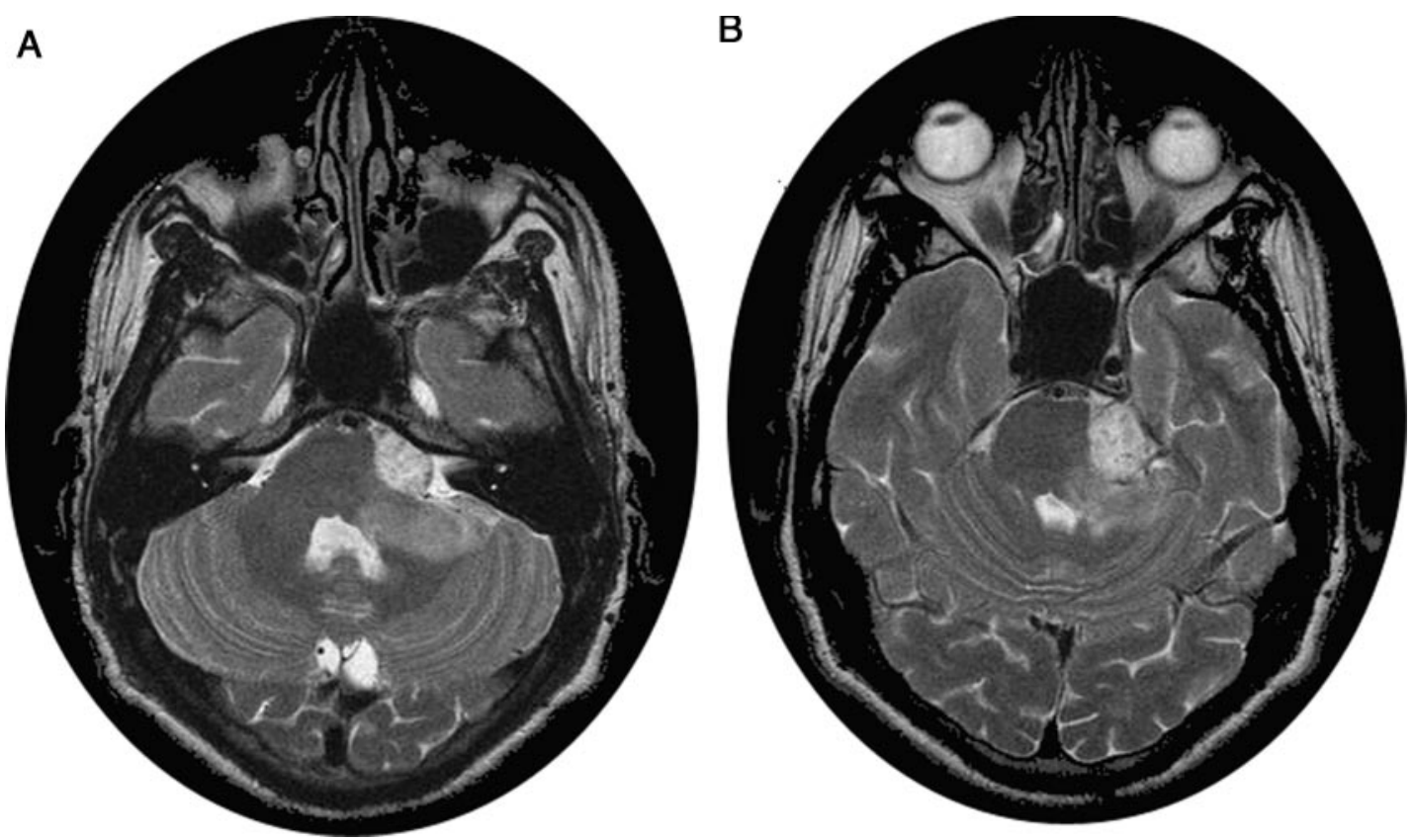

A $22 \times 10 \times 23 \mathrm{~mm}$ left cerebellopontine angle mass indents the pons and cerebellum and extends to left petrous apex. It has high signal on T2 (A, B), low signal on T1, and vividly enhances with contrast.

A 30-year-old man presented with episodic severe left orbital pain associated with ipsilateral lacrimation, rhinorrhea, and conjunctival injection. Attacks lasted 15-60 minutes, occurred two to four times per month, and partially resolved with verapamil and sumatriptan. Examination was normal apart from reduced sensation over the left maxillary nerve. MRI demonstrated a tumor arising from the left trigeminal nerve (figure, A and B). The tumor was surgically resected and the headaches resolved completely. Histology confirmed a grade II choroid meningioma. Many headache experts recommend mandatory neuroimaging in patients with new onset trigeminal-autonomic cephalalgia to exclude secondary causes, especially in those with atypical features such as cranial neuropathies or unusual periodicity.

Jane Alty, MRCP (UK) MA, Peter Kempster, MD MRCP (UK), FRACP, and Sanjay Raghav, FRACP, Melbourne, Victoria, Australia

Disclosure: The authors report no disclosures.

Address correspondence and reprint requests to Dr. Sanjay Raghav, Monash Medical Centre, 246 Clayton Road, Melbourne, Victoria 3168, Australia; sanjay.raghav@southernhealth.org.au 


\section{Neurology}

\section{Cluster-like headache secondary to trigeminal meningioma \\ Jane Alty, Peter Kempster and Sanjay Raghav \\ Neurology 2008;70;1938 \\ DOI 10.1212/01.wnl.0000312286.64144.2e}

This information is current as of May 12, 2008

\section{Updated Information \&} Services

Permissions \& Licensing

Reprints including high resolution figures, can be found at: http://n.neurology.org/content/70/20/1938.full

Information about reproducing this article in parts (figures,tables) or in its entirety can be found online at:

http://www.neurology.org/about/about_the_journal\#permissions

Information about ordering reprints can be found online:

http://n.neurology.org/subscribers/advertise

Neurology ${ }^{\circledR}$ is the official journal of the American Academy of Neurology. Published continuously since 1951, it is now a weekly with 48 issues per year. Copyright . All rights reserved. Print ISSN: 0028-3878. Online ISSN: 1526-632X.

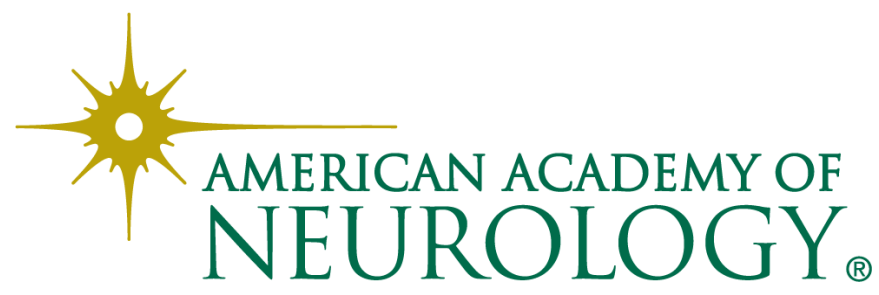

